\title{
The Analysis of Bank Deposits through Spatial Modelling by Provinces
}

\author{
Ozlem Deniz Basar ${ }^{1} \&$ Elif Guneren Genc ${ }^{2}$ \\ ${ }^{1}$ Department of Statistics, Istanbul Commerce University, Istanbul, Turkey \\ ${ }^{2}$ Department of International Trade, Istanbul Commerce University, Istanbul, Turkey \\ Correspondence: Elif Guneren Genc, Department of International Trade, Istanbul Commerce University, Istanbul, \\ Turkey.
}

Received: November 19, 2015

Accepted: December 8, 2015 Online Published: December 28, 2015

doi:10.5430/ijfr.v7n1p91

URL: http://dx.doi.org/10.5430/ijfr.v7n1p91

\begin{abstract}
One of the most important financial resources of banking sector is deposit value. Banks collect money from public and transfer it to economy by giving credits to firms and establishing companies. It is widely acknowledged that bank deposits are concentrated in particular provinces of Turkey. In this context, it has become important to determine the impacts of changes of deposits, which provides liquidity for economy, on provincial economies. The aim of this study is to analyse variables that are considered to explain total bank deposits and to identify spatial interaction on deposit changes on the provincial bases. The existence of spatial effect by provinces in Turkey was identified in terms of total bank deposits. Accordingly, it was determined that the provinces of Istanbul, Ankara and Mardin were different from other provinces.
\end{abstract}

Keywords: spatial models, Moran I Test, banks, deposits

\section{Introduction}

Financial system has a significant position among the determinants of performances of national economies. For the supply of necessary financial means that are needed for investments, the primary sources are banks, which act as engines of real sector and mediators to pass through household savings to economy in exchange for particular profits. Banks are strategic and significant actors and financial mediators within the financial system; they also play a fundamental role in economic growth.

As banks operate as commercial enterprises for profit maximization, they also have several functions as parts of the economic system. Banking activities can be classified into three groups: deposit collection, distribution of credits and accomplishment of certain banking services. Deposits are among the main sources of banks. Banks collect money from public and transfer it to economy by giving credits to firms and establishing companies

Figure 1 presents deposit shares in Turkey by province in 2014. Istanbul, which has the highest share, is followed by Ankara and Izmir respectively. The city of Istanbul's deposits with $49.3 \%$ share are almost equal to the half of deposits provided by 81 provinces in Turkey.

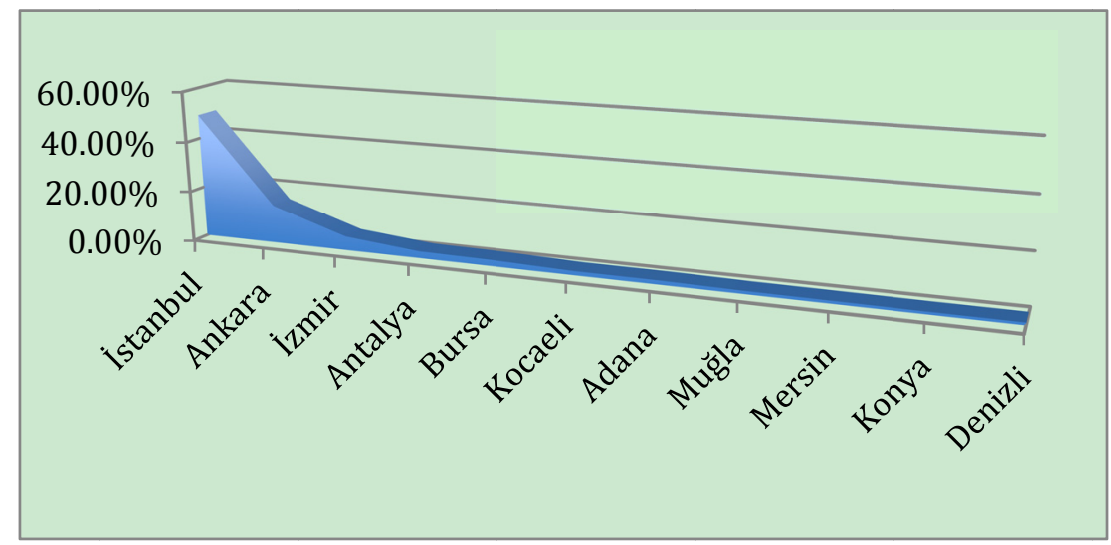

Figure 1. Total deposit shares by province in 2014

https://www.tbb.org.tr/tr/banka-ve-sektor-bilgileri/istatistiki-raporlar/59 
Banking services for customers such as collection of deposits, distribution of credits and provision of financial services, bank branches are of particular importance. Due to increase of competition in the banking sector, banks try to remain close to their customers in order to receive deposits as much as possible and keep these deposits with higher interest rates. Therefore branches for banks mean to reach more customers and consequently more revenue.

In addition banks reduce costs and save time with the help of advancing technologies and have begun to use external services. For example, the number of ATMs in Turkey increased $91.2 \%$ and the number of POS devices increased $42.6 \%$ in the last five years. This situation demonstrates that consumer behaviours of customers and expectations of enterprises from the banking sector have been changed in Turkey.

As it is in each sector, components of competitiveness are effective in determination of sector's dynamics. Banks have important role in funding of small and medium-sized enterprises (SME). Micro-scaled stability leads to a macro-scaled stability. For this reason, the number of SMEs in provinces is important. Moreover, another element that is not to be underestimated in financial relations between enterprises and banks is the necessity to obtain financial support in a most cost-effective way as possible in order to realise capital investments and consequently increase of production. In this situation, SMEs should be informed in order to maintain marginal efficiency and in consideration with environmental factors. Chambers of industry and commerce in provinces become part of the activity.

Chambers of industry and commerce in Turkey were founded to contribute domestic and foreign trade in provinces. Chambers of industry and commerce are vital institutions; they help to resolve current issues in the sector, deliver any kind of information to enterprises, deliver political and economic developments for the benefit of enterprises and increase share of provinces from international trade.

Due to the changing use of economic space in the early $20^{\text {th }}$ century, spatial effect has been included in economic analysis. After the second half of the century, spatial effects began to include economically developed theories and regional economies created their own purposes and needs. In Turkey, it is observed that particularly deposits are concentrated in certain provinces. In this context, it has become important to determine the effect of deposit changes in provinces, as this change brings liquidity for economy. The aim of this study is to identify the impacts of spatial interaction on deposit movement on the basis of provinces in Turkey.

\section{Literature Review}

Nowadays, the variation of financial instruments in the banking sector leads to the use of different analytical approaches. This situation has revealed that these interactions should be analysed in consideration with different perspectives. Different studies recently analysed the effects of spatial differences on financial instruments.

Ansong and Chowa (2015)'s study analyses distribution of bank branches and their indicators in Ghana through spatial analysis. The study founded out that southern urban areas of Ghana had better variation of financial services and better accessibility in comparison to the northern rural areas.

Uchino (2014) investigated geographical segmentation of bank deposit interest rates in the Japanese banking sector with the help of panel co-integration model. The model consisted of data that belong to 47 provinces between 1999 and 2010. The empirical results of this paper show a significant negative correlation between regional market concentration and pass-through, which implies the existence of geographical market segmentation.

Marshall (2013) investigated the impacts of global banking crisis of 2007-2009 on England. Marshall stated that banking crisis in England began in London; it created a domino effect and spread to other financial sectors through spatial interaction in an integrated way. The study indicated that in addition to alternative opportunities, organisational and spatial centralisation for deepening of financial sector has become an encouraging element of oppression.

Forsyth (2013)'s study analysed 157 Federal Deposit Insurance Corporations and discussed regional risks taken by banks in the process of economic growth between 2001 and 2007. Pacific Northwest banks significantly increased their share of $100 \%$ risk-weighted assets, largely through commercial real estate lending. Asset size, market concentration, age, metropolitan statistical area-location, and balance sheet capacity for risk-taking are statistically significant predictors of the change in the share of $100 \%$ risk-weighted assets over the period of interest.

In Turkey, Hazar and Babuscu (2013) conducted a regional analysis including development of credits and deposits in the Turkey banking sector between 2005 and 2011. They identified that savings performance of larger provinces were better and despite low purchasing power in the eastern and south-eastern provinces, their savings were lesser than credit amounts. 
In determination of location of credit unions in America, Deller and Sundarom-Stukel (2012) employed similar location models that are based on central place theory. Credit unions in America are regarded as community-based strategies that are designed to fill gaps in financial markets. The used spatial lagged model as OLS and Tobit estimators were biased and inconsistent coefficient. They find that spatial estimators generally performed better than the spatial estimators, and there is significant spatial heterogeneity in some of the determinants of credit union concentrations.

Valiullin and Merzlyakova (2011)'s study analysed spatial development trends of the Russian banking sector. These scholars particularly focus on determinant factors of spatial structure in the banking system, as Russia is vast country with many macroeconomic differences. The results indicated that Russian banking system has a heterogeneous structure and significant amount of polarisation.

Filbeck, Preece, Woessner and Burgess (2010)'s study compared deposits and market shares of 8 districts in America for community and regional banks between 2001 and 2008. Despite the highness of community banks' market share, regional banks have more deposits.

Liu, Molyneux and Wilson (2010) investigated the impacts of regional economic conditions and risks of banks in European Banking. The identified that particularly regionally, an increase in unemployment was parallel with increase of risks. They found out a non-linear correlation between bank competitions and stability.

Lima and Resende (2008) investigated regional inequalities in financial flows in Brazil. They established regional financial inequality index with 6 months-data ranging from the second half of 1994 to the second half of 2000. The index was evaluated in accordance with deposits and credit operation results in regions. The study presented two major results. Firstly, private banks particularly for deposits created non-negligible inequality; secondly and conversely public banks supported regional development.

\section{Methodology}

Qualitative approaches to geographical systems can be achieved through the use of spatial methods. These methods were included in the literature after Cliff and Ord's studies in 1973. Odland (1988)'s "spatial autocorrelation" studies, Boots and Getis (1988)'s "point pattern analyses", Anselin (1988) and Ripley (1988)'s "spatial econometrics and spatial statistics" studies are considered as significant steps in development of spatial analyses. Nowadays, spatial data and analyses, which are widely used thanks to the advance of computer technologies, are gradually included more in the current literature. The most commonly applied areas are geology, soil sciences, image analysis, epidemiology, agricultural science, ecology, forestry, astronomy and atmospheric sciences.

\subsection{Spatial Autocorrelation}

Many scholars that work on spatial statistics are mostly interested in autocorrelations, which mean the dependency of measurement of spatial data that consist of spatial observations. Because of this dependency, "classical" statistical modelling and "spatial" modelling are different from each other. Application of classical statistical methods on spatial data would damage competence and consistency assumptions of results (Schabenberger \& Gotway, 2005).

Some of the statistics that are used to calculate spatial autocorrelation are The Moran Coefficient (Moran's $I$ - MC) and Geary Ratio (Geary's C - GR). As this study employed only Moran Coefficient, only this concept was explored.

\section{Moran Coefficient}

In calculation of this coefficient, which is based on spatial weights, the following equation is used. Here, $w_{i j}$ refers to row standardized weight matrix W's components; $\mathrm{n}$ to number of sampling unit and $y$ corresponding variable. Moran $I$ coefficient is the following:

$$
I=\frac{n \sum_{i} \sum_{j \neq i} w_{i j}\left(y_{i}-\bar{y}\right)\left(y_{j}-\bar{y}\right)}{\left(\sum_{i} \sum_{j \neq i} w_{i j}\right) \sum_{i}\left(y_{i}-\bar{y}\right)^{2}}
$$

Moran $I$ coffecient's mean and variance were calculated as follows (Ward \& Gleditsch, 2008, 23):

$$
\begin{gathered}
E(I)=-\frac{1}{(n-1)} \\
\operatorname{Var}(I)=\frac{n^{2}(n-1) \frac{1}{2} \sum_{i \neq j}\left(w_{i j}+w_{j i}\right)^{2}-n(n-1) \sum_{k}\left(\sum_{j} w_{k j}+\sum_{i} w_{i k}\right)^{2}-2\left(\sum_{i \neq j} w_{i j}\right)^{2}}{(n+1)(n-1)^{2}\left(\sum_{i \neq j} w_{i j}\right)^{2}}
\end{gathered}
$$


For the calculated values:

- If $\mathrm{MC}$ value is close to +1 ', there is a strong positive autocorrelation

- If $\mathrm{MC}$ value is close to -1 , there is a strong negative autocorrelation

- If MC value is close to $-1 /(n-1)$, these values are random (Arlinghaus, 1995, 27).

\subsection{Spatial Regression Analysis}

It is convenient to apply spatial regression analyses when residual values are dependent and when there are spatial variables (Chi \& Zhu, 2008). For this reason, it is important to establish spatially structured models for validity and reliability of the study after examination of spatial dependency. The next step is about spatial weights matrices. They are mostly made up by coding contiguous regions with one and the others with zero. However, it is generally seen in practice that not only contiguity but also different features affect the model. Therefore, weights functions, which contain different effects than contiguity allowing obtaining weights matrices, have been generally used in recent times. There are many methods to create weights matrices. This study only employed k-nearest neighbour method; therefore only this matrix is explained.

\section{k-nearest neighbour}

If nearest neighbour matrix;

$$
\begin{aligned}
\mathrm{W}_{\mathrm{ij}} & =1, \text { if } \mathrm{j} \text { is the nearest neighbour of } \mathrm{i} \\
& =0, \text { on other occasions. }
\end{aligned}
$$

The nearest neighbour is expressed as the closest observation to i. observation. This (nxn) dimensional matrix has an asymmetrical structure (Fotheringham \& Rogerson, 2009).

\section{Spatial autoregressive models}

In spatial structure, autoregressive models show data on the point $\mathrm{s}$ as linear composition of neighbour values. Autoregressive data are considered to include spatial dependency.

Autoregressive group of models, which are created through data acquired from a spatial sample, are shown as the following:

$$
\begin{gathered}
\mathbf{y}=\rho \mathbf{W}_{1} \mathbf{y}+\mathbf{X} \beta+u \\
u=\lambda \mathbf{W}_{2} u+\varepsilon \\
\varepsilon \sim N\left(0, \sigma^{2} I_{n}\right)
\end{gathered}
$$

Here, $\mathrm{y}$ refers to $\mathrm{nx} 1$ dimensional dependent variables vector; $\mathrm{X}$ refers to $\mathrm{nxk}$ dimensional independent variables vector; $\mathrm{W}_{1}$ and $\mathrm{W}_{2}$, known nxn dimensional spatial weights matrix. Many other spatial models were derived from this group of models (LeSage, 1999).

This generalised scene shows possible derivative models in the following if necessary regulations are made:

Table 1. Spatial models and equations

\begin{tabular}{ll} 
Model & Equation \\
\hline \hline Spatial Lag Model & $y=\rho W y+X \beta+\varepsilon$ \\
& $\varepsilon \sim N\left(0, \sigma^{2} I_{n}\right)$ \\
Spatial Error Model & $y=X \beta+\lambda W u+\varepsilon$ \\
& $\varepsilon \sim N\left(0, \sigma^{2} I_{n}\right)$ \\
\hline
\end{tabular}




\subsection{Spatial Effects}

The existence of spatial effects leads to invalidity of least squares estimation (LSE) Therefore there are many tests in the literature concerning definition of models. In this study, one of the most well known methods, the Lagrange multiplier (LM) method was employed.

LM test, which was developed by Burridge (1980) for spatial error dependency, is calculated as follows:

$$
\text { LM-Err }=\left(e^{\prime} W e / s^{2}\right)^{2} / T
$$

Here e refers to LSE residual vector; W refers to spatial weights matrix and $s^{2}=e^{\prime} e / N$ and

$T=\operatorname{tr}\left(W^{\prime} W+W^{2}\right)$. It is known that this statistics is compatible with 1 degree of freedom and chi-square distribution.

Dependency test of spatial lag, on the basis of classical regression essentials, was showed by Anselin (1988) in the following:

$$
\mathrm{LM}-\mathrm{Lag}=\left(e^{\prime} W y / s^{2}\right)^{2} /\left(R J_{\rho-\beta}\right)
$$

Here, e refers to LSE residual vector; y refers to dependent variable and $R J_{\rho-\beta}=\left[T+(W X \beta)^{\prime} M(W X \beta) / s^{2}\right]$. In this equation WX $\beta$ refers to spatial lags that are estimated from least squares regression model and $M=I-X\left(X^{\prime} X\right)^{-1} X^{\prime}$ is the projection matrix. Similar to the previous statistics, this one is also compatible with 1 degree of freedom and chi-square distribution.

\section{Implementation}

Deposits are one of the the most importance source of revenue for banks in the banking sectors. Banks pass through deposits to economy by using several ways. It is known that there are many factors influencing deposit values of banks. The aim of this study is to determine variables influencing deposit values of banks. In doing so, the study also aims to include and analyse the neighbouring provinces that are located in the vicinity of the provinces, where above-mentioned banks are present. The study employed spatial regression analysis in order to demonstrate effects of neighbourliness.

This study considered all provinces of Turkey. The study used the following variables, which were obtained from official websites of The Banks Association of Turkey and The Confederation of Merchants and Craftsmen: total deposits of banks in 81 provinces (Turkish Liras) (LDB), number of registered small and medium sized enterprises (LRE) in a province, total number of active chambers of commerce and industry in a province (LCC), total amount of credits that banks give in their own provinces (LAC), number of branches of banks in a province (LBB) and number of active POS devices (LPOS). As units of these variables are different, firstly logarithmic transformation was applied to all variables.

The next step was regression analysis in order to determine variables that influence total deposits. Necessary assumptions to employ regression analysis were examined and as no deterioration was detected, regression analysis was made. Table 2 summarises the results concerning the model that was obtained after this analysis.

Table 2. OLS model results concerning Turkey's 81 provinces

Dependent variable: LDB

\begin{tabular}{lc}
\hline \hline Constant & $1.8099^{* * *}$ \\
& $(0.6766)$ \\
LAC & 0.2532
\end{tabular}


$(0.1623)$

$\begin{array}{lc}\text { LPOS } & 0.7448^{* * *} \\ & (0.1890) \\ \text { LBB } & 0.3752^{* *} \\ & (0.1764) \\ \text { LRE } & 0.1057^{* *} \\ & (0.0525) \\ \text { LCC } & 0.2599^{* * *} \\ & (0.0952) \\ n & 81 \\ \text { F Statistics } & 17.39^{* * *} \\ D-W \text { Stat } & 1.9400 \\ \text { Adj. } R^{2} & 50.61 \%\end{array}$

According to results, the variables that were found significant can be interpreted as follows. LPOS (number of active POS devices), LBB (number of branches of banks in a province), LRE (number of registered small and medium sized enterprises) and LCC (total number of active chambers of commerce and industry in a province) have no increasing impact on total deposits of banks. In this investigation, which was made in consideration of all provinces in Turkey, provinces are considered to affect each other through spatial interaction. For this reason, Moran's I statistics were calculated and tested in order to prove the existence of spatial interaction (spatial autocorrelation).

Table 3. Moran Test

Global Moran's I for Regression Residuals

\begin{tabular}{ll}
\hline \hline Moran I statistic standart deviate & 1.8917 \\
$\mathrm{p}$-value & 0.0292 \\
\hline
\end{tabular}

As seen on Table 3, spatial interaction was identified $(\mathrm{p}<0.05)$. Spatial regression analysis was employed in order to determine and abolish the impacts of spatial interaction. For this analysis, a load referring to neighbourliness is needed. There are many load methods to use. This study took coordinates of provinces into consideration and determined four neighbours. This method is called k-nearest neighbour in the literature.

In determination of spatial regression model, it is necessary to examine several diagnostics. These are Lagrange Multiplier (LM) diagnostics, LM error test, Robust LM error test, LM Lag test and Robust LM lag test, which are used to determine spatial dependency. The results of these tests are presented on Table 4.

Table 4. Lagrange multiplier diagnostics

Lagrange Multiplier Diagnostics for Spatial Dependence

\begin{tabular}{lll}
\hline \hline LMError (df) & $2.1411(1)$ & 0.1434 \\
RobustLMError (df) & $0.0002(1)$ & 0.9878 \\
LMLag (df) & $3.6875(1)$ & 0.0502 \\
RobustLMLag (df) & $1.5466(1)$ & 0.1211 \\
\hline
\end{tabular}

In examining respective results, LM lag test produced significant results. Therefore, the model was decided to be designed as spatial lag model to investigate spatial effects. The results concerning spatial lag model are shown on Table 5 . 
Table 5. Spatial LAG model of Turkey's 81 provinces

\begin{tabular}{lc}
\multicolumn{2}{c}{ Dependent variable: LDB } \\
\hline \hline Constant & 0.8426 \\
& $(0.7736)$ \\
LAC & $0.2810^{*}$ \\
& $(0.1519)$ \\
LPOS & $0.6748^{* * *}$ \\
& $(0.1784)$ \\
LBB & $0.3066^{*}$ \\
& $(0.1666)$ \\
LRE & $0.1068^{* *}$ \\
& $(0.0491)$ \\
LCC & $0.2863^{* * *}$ \\
& $(0.0894)$ \\
Rho & 0.22556 \\
LR Test Value & $3.5705^{* *}$ \\
Wald Statistics & $4.0824^{* *}$ \\
Log likelihood & 62.8250 \\
AIC & -109.6500 \\
LM Test & 0.0063 \\
$n$ & 81 \\
\hline
\end{tabular}

The analysis of this model showed that coefficients concerning all variables including total credit variable (LAC) but constant variable, which were found insignificant during classic regression analysis, were identified as significant.

As both total amount of credits variable (LAC) and spatial effect have significant impacts on deposits, it is decided that working with spatial model is appropriate. The graph of estimations from this model is given on Figure 2.

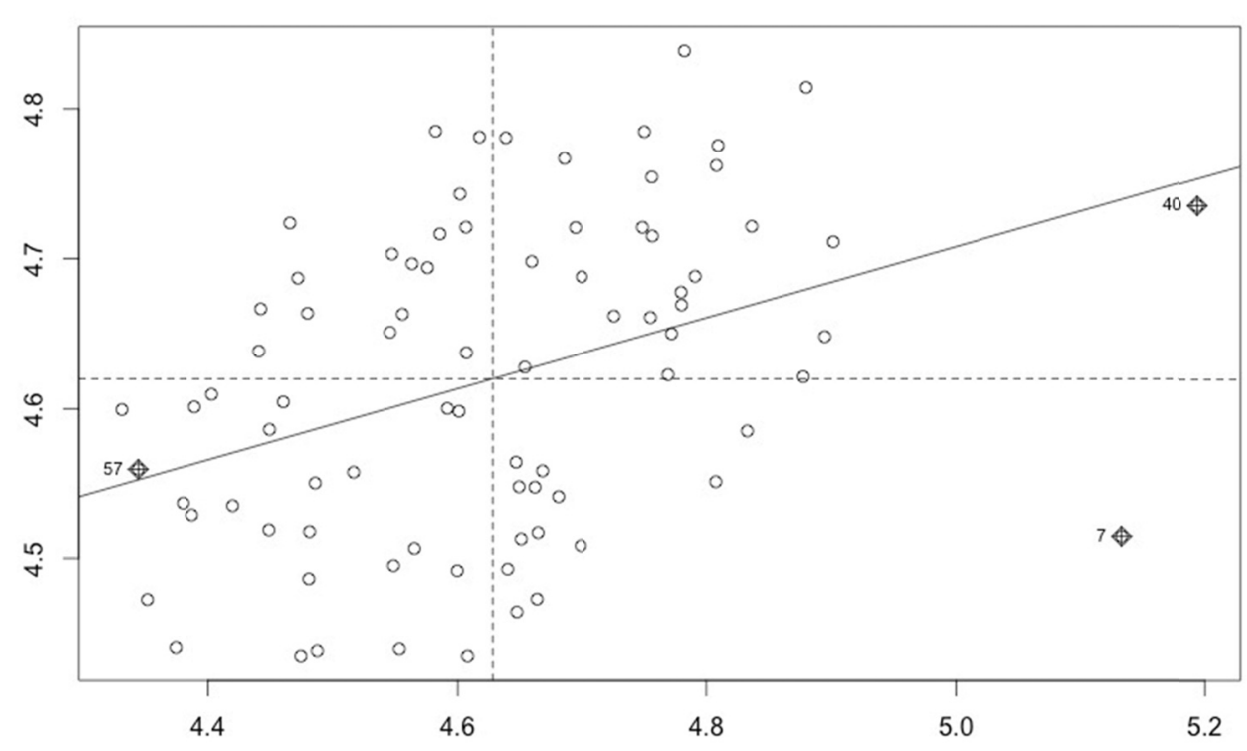

Figure 2. Moran plot of dependent variable and spatially lag dependent variable 
As shown in Figure 2 represents differential provinces. Among the results from 81 provinces, Istanbul (number 40), Ankara (number 7) and Mardin (number 57) are different from other provinces. This is an expected result for Istanbul as it is the largest city in Turkey and it is the most active city in terms of working sectors. Ankara is the capital of Turkey and at the same time the second most developed city; therefore it is different from others. Mardin, although its region does not reach sufficient levels of economic development, it has a different position as a result of estimations that are based on spatial model. This situation indicates that Mardin has a different structure from other provinces in the region; it has become an active and directing province for others in terms of deposit movements.

After creation of spatial model, Moran test was applied to analyse whether spatial effect was removed or not. The results can be seen on Table 6 .

Table 6. Moran's I Test results for spatial lag model

Moran's I test under Randomisation

\begin{tabular}{ll}
\hline \hline Moran I statistic standart deviate & -0.0115 \\
p-value & 0.5046 \\
\hline
\end{tabular}

Test results indicate that spatial effect on the model was removed. The effects of neighbourliness of provinces were also included in the model.

Table 7. Effects on predicted LDB if Istanbul had a LDB value of 1

\begin{tabular}{ll}
\hline \hline Country & Impact \\
\hline Kocaeli & 0.041 \\
Bursa & 0.018 \\
Çanakkale & 0.003 \\
Balıkesir & 0.003 \\
Sakarya & 0.001 \\
Bilecik & 0.001 \\
\hline
\end{tabular}

Mutual effects of neighbouring provinces on each other can be examined by equilibrium analyses with the help of spatial model. Here, Istanbul was taken into consideration as the most different province in terms of working sector. Then it was determined to what extend the changes of total amount of deposits in Istanbul might affect neighbouring provinces. The results are presented on Table 7.

With regard to neighbour relations, the provinces of Kocaeli, Bursa, Çanakkale, Balıkesir, Sakarya and Bilecik would experience the most significant impacts from changes in Istanbul. As Table 7 presents, $1 \%$ increase in LDB values in Istanbul might cause $0,041 \%$ increase in Kocaeli's LDB value, $0.018 \%$ in Bursa, $0.003 \%$ in Çanakkale and Balıkesir and $0.001 \%$ in Sakarya and Bilecik.

\section{Conclusions}

One of the most important financial resources in the banking sector is total deposit value. The highness of this value can be regarded as the most important factor in continuation of banking transactions and determination of credibility of banks. There are many factors influencing total deposit values of banks. The study analysed variables that are thought to affect total deposit values of banks. Thanks to research findings, spatial vicinity of provinces is considered to affect results, alongside variable explaining total deposits. For this reason, with the assistance of nearest neighbour, weights matrix was formed and modelling was spatially repeated.

Total amount of credits, which are thought to affect total deposits in banking considerably, was found significant in spatial model in contrast to the classical model. Nevertheless as a result of the tests, spatial autocorrelation and interaction provinces in terms of their locations were identified. Due to the identification of spatial effect and significant impacts of total amount of credits variable (LAC) on deposits alongside other variables, spatial regression model was preferred instead of classical regression model. 
The study also analysed geographical locations of provinces and their neighbouring status. It was found out that Turkey's two largest provinces; Istanbul and Ankara were different from other provinces in terms of total bank deposits. Today, about $50 \%$ of total deposits are concentrated in Istanbul. In addition, $43.2 \%$ of credits is used in Istanbul, which is an intersection point of land and naval trade routes. Business circles are particularly located in Istanbul; so this differentiation is an expected result. Ankara, with its political and strategic advantages due to its capital status, developed industry and human resources, is different from other provinces. Moreover, the concentration of state institutions and organisations and public financial agencies in this city play a role in this result. The province of Mardin, which is different from traditional economic structure of the South-eastern Anatolian Region with its small-scale industry and commerce, has unique characteristics. This situation was revealed in analysis results; the province of Mardin has become an active and directing province for other provinces in the vicinity.

In this study, only k-nearest neighbour matrix was used and spatial modelling was applied in order to remove spatial effect. Different characteristics of provinces were brought into the forefront by using weights matrices with different structures. Further studies might analyse interactions of provinces in terms of total deposits through establishing various models.

\section{References}

Anselin, L. (1988). Lagrange multiplier test diagnostics for spatial dependence and spatial heterogeneity. Geographical Analysis, 20, 1-17. http://dx.doi.org/10.1111/j.1538-4632.1988.tb00159.x

Ansong, D., \& Chowa, G. (2015). Spatial analysis of the distribution and determinants of bank branch presence in Ghana. Internation Journal of Bank Marketing, 33(3), 201-222. http://dx.doi.org/10.1108/IJBM-09-2013-0103

Arlinghaus, S. L. (1995). Practical Handbook of Spatial Statistics. Boca Raton: CRC Press.

Boots B. N., \& Getis, A. (1988). Point pattern analysis (8nd ed). London: Sage Scientific Geography Series.

Burridge, P. (1980). On the Cliff-Ord test for spatial autocorrelation. Journal of the Royal Statistical Society B, 42 , $107-108$.

Chi, G., \& Zhu, J. (2008). Spatial Regression Models for Demographic Analysis. Population Research and Policy Review, 27, 17-42. http://dx.doi.org/10.1007/s11113-007-9051-8

Cliff, A. D., \& Ord, J. K. (1973). Spatial Autocorrelation. London: Pion Limited.

Deller, S., \& Sundarom-Stukel, R. (2012). Spatial patterns in the location decisions of US credit unions. Annals of Regional Science, 49(2), 417-445. http://dx.doi.org/10.1007/s00168-011-0457-1

Filbeck, G., Preece, D., Woessner, S., \& Burgess, S. (2010). Community banks and deposit market share growth. International Journal of Bank Marketing, 28(4), 252-266. http://dx.doi.org/10.1108/02652321011054954

Forsyth, G. D. (2013). Trough to peak: a note on risk-taking in the Pacific Northwest's banking sector, 2001-2007. Contemporary Economic Policy, 31(2), 378-391. http://dx.doi.org/10.1111/j.1465-7287.2011.00305.x

Fotheringham, A. S., \& Rogerson, P. A. (2009). The SAGE Handbook of Spatial Analysis. London: SAGE Publications.

Hazar, A., \& Babuscu, S. (2013). Turkish banking sector credit-deposit developments regionally analysis (2005-2011). Journal of Cankırı Karatekin University Economics and Administrative Sciences, 3(1), 93-119.

LeSage, J. P. (1999). The Theory and Practice of Spatial Econometrics. Department of Economics, University of Toledo. Retrieved from http://www.spatial-econometrics.com/html/sbook.pdf

Lima, M., \& Resende, M. (2008). Banking and regional inequality in Brazil: an empirical note. Brazilian Journal of political Economy, 28(4), 669-677. http://dx.doi.org/10.1590/S0101-31572008000400008

Liu, H., Molyneux, P., \& Wilson, J. O. S. (2010). Competition and stability in European banking: a regional analysis. Bangor Business School Working Paper. United Kingdom. Retrieved from http://www.bangor.ac.uk/business/docs/BBSWP10019.pdf

Marshall, J. N. (2013). A geographical political economy of banking crises: A peripheral region perspective on organisational concentration and spatial centralisation in Britain. Cambridge Journal of Regions, Economy and Society, 6(3), 455-477. http://dx.doi.org/10.1093/cjres/rst002

Odland, J. D. (1988). Spatial Autocorrelation. New York: Sage Publications. 
Ripley, B. D. (1988). Statistical Inference for Spatial Processes. Retrieved from http://dx.doi.org/10.1017/CBO9780511624131

Schabenberger, O., \& Gotway, C. A. (2005). Statistical Methods for Spatial Data Analysis. Boca Raton: Chapman \& Hall/CRC.

$\begin{array}{llllll}\text { Türkiye } & \text { Bankalar } & \text { Birliği. (2015). } & \text { Istatistiksel } & \text { Raporlar. } & \text { Retrieved }\end{array}$ https://www.tbb.org.tr/tr/banka-ve-sektor-bilgileri/istatistiki-raporlar/59

Türkiye Esnaf ve Sanatkarları Konfederasyonu. (2015). Illlere göre esnaf, işyeri, nüfus ve oda bilgileri. Retrieved from http://www.tesk.org.tr/tr/calisma/sicil/4.pdf

Uchino, T. (2014). Bank deposit interest rate pass-through and geographical segmentation in Japanese banking markets. Japan and the World Economy, 40, 37-51. http://dx.doi.org/10.1016/j.japwor.2014.02.003

Valiullin, K. K., \& Merzlyakova, S. L. (2011). Tendencies towards the spatial concentration of the Russian banking sector. Studies on Russion Economic Development, 22(5), 526-534. http://dx.doi.org/10.1134/S1075700711050133

Ward, M. D., \& Gleditsch, K. S. (2008). Spatial Regression Models. New York: Sage Publications Series: Quantitative Applications in the Social Sciences. 